\title{
Sensors Network based Accident Alert System
}

\author{
Sana ${ }^{1}$, Dr. Ravindra P Rajput ${ }^{2}$ \\ ${ }^{1}$ M.Tech Scholar, Dept. of VLSI Design \& Embedded Systems, VTU Centre for PG Studies, Kalaburagi, India \\ ${ }^{2}$ Professor, Dept. of VLSI Design \& Embedded Systems, VTU Centre for PG Studies, Kalaburagi, India
}

\begin{abstract}
Vehicle accident is the paramount thread for the people's life which causes a serious wound or even dead. The automotive companies have made lots of progress in alleviating this thread, but still the probability of detrimental effect due to an accident is not reduced. Vibration sensor, Global System for Mobile (GSM) and Global Positioning System (GPS) are used in this system. After taking places of an accident, the system delivers a short message to a nearby rescue team and police station via GSM module. The message includes the longitude and latitude values of the location. A rescue team can instantly trace the location of the vehicle tapping geographical coordinates in Google earth or any other GPS viewer application to help wounded people. Most of the previous system comprised of multiple sensors for detecting accident which increased the cost of the project. But, the proposed model includes only one vibration sensor; thus it reduces the cost of multiple sensor and the complexity of interfacing. So, it will be affordable for vehicle owners. This application is integrated with an external pressure sensor to extract the outward force of the vehicle body. It measures speed and change of tilt angle with GPS and accelerometer sensors respectively. By checking conditions, this application also capable of reducing the rate of false alarm.
\end{abstract}

Keywords-Accident detection system; force sensor; Global Positioning System (GPS); Global System for Mobile (GSM)

\section{INTRODUCTION}

The automotive industry around the world has shown a tremendous enhancement in its production over the recent years. Millions of vehicles are being produced annually. But along with these, the accident rates are also getting significantly increased. As a result, even the optimistic nature of people has become worried while going outside. United States Department of Transportation data for 2005 from the Fatality Analysis, Reporting System show that for passenger cars, 18.62 fatal crashes occur per 100,000 registered vehicles. In 2009, 33,808 people died in vehicle traffic crashes only in USA [1].

Most of the accidents occur due to human negligence, such as reckless driving, lack of good infrastructure, etc. An immediate rescue process after an accident can be considered as a tightrope walk between life and death. Any fractional time delay of arriving medical help can cost the life of the victims. A study by Virtanen et al. shows that $4.6 \%$ of the fatalities in accidents could have been prevented only in Finland if the emergency services could be provided at the place of the accident at the proper time [2]. As such, an efficient automatic accident detection with an automatic notification to the emergency service with the accident location is a prime need to save the precious human life.

As smart phones become such an important part of our life, it is feasible to use smart phones in a post-accident fatality prevention system. Our application uses the GPS receiver in phone to detect the rapid change of deceleration that occurred at accident time. It also takes the change of pressure from the pressure sensor and the change of tilt from an accelerometer sensor in a Smartphone. By detecting these three conditions as accident detection, this android app send the accident location for emergency help. An emergency switch option also added to this app which provides a chance to driver for sending alert message without checking accident detection condition. Therefore, our contribution can be listed as follows:

- Construction of an efficient automated vehicle accident detection system using Arduino.

- Develop a framework for reducing false alarm of vehicle accident detection.

- Dispatch automatic emergency accident alert message to relative, nearest police station and hospital.

We have discussed on some relevant papers in section II. In section III we have chronicled the system functionality with technical details. Later we have shown the implementation result with experimental data, functional and subjective evaluation of our application. In the end, we discussed about the challenges and future extension of our work.

\section{RELATED WORKS}

Mobile devices, especially Smart phones have been deployed as floating traffic probes and sensors in many applications, both academically and commercially [3]. These applications include road conditions survey, traffic conditions monitoring [4] and accident detections [5]. All of these abilities are essential to an Intelligent Transport System (ITS), which aims to reduce traffic congestion and enhance traffic safety [6]. Real-time traffic accident prediction focuses on the change of traffic conditions before an accident occurrence, while traffic incident detection studies are concerned with the change of traffic conditions after an incident occurrence [7]. However, the performance of these detection and prediction system is greatly restricted by the number of monitoring sensor, available fund, the algorithms used to confirm an accident, weather, traffic flow etc.An acoustic accident detection method is proposed by D. A. Whitney and J. J. Pisano [8]. There are possibilities of false alarm in the system and also does not guarantee the occurrence of an accident. S. Amin et al. proposed a method of accident detection and reporting system using GPS, GPRS and GSM Technology[9].

C. Saiprasert et al. propounded a reporting system in case of dangerous driving using android [10]. Jung Lee described an accident detection system on a highway by tracking the vehicle [11]. We have used pressure sensor, GPS and 
accelerometer to detect a real alarm and dispatch alert message to nearby police station and health care center.

\section{SYSTEM DESCRIPTION}

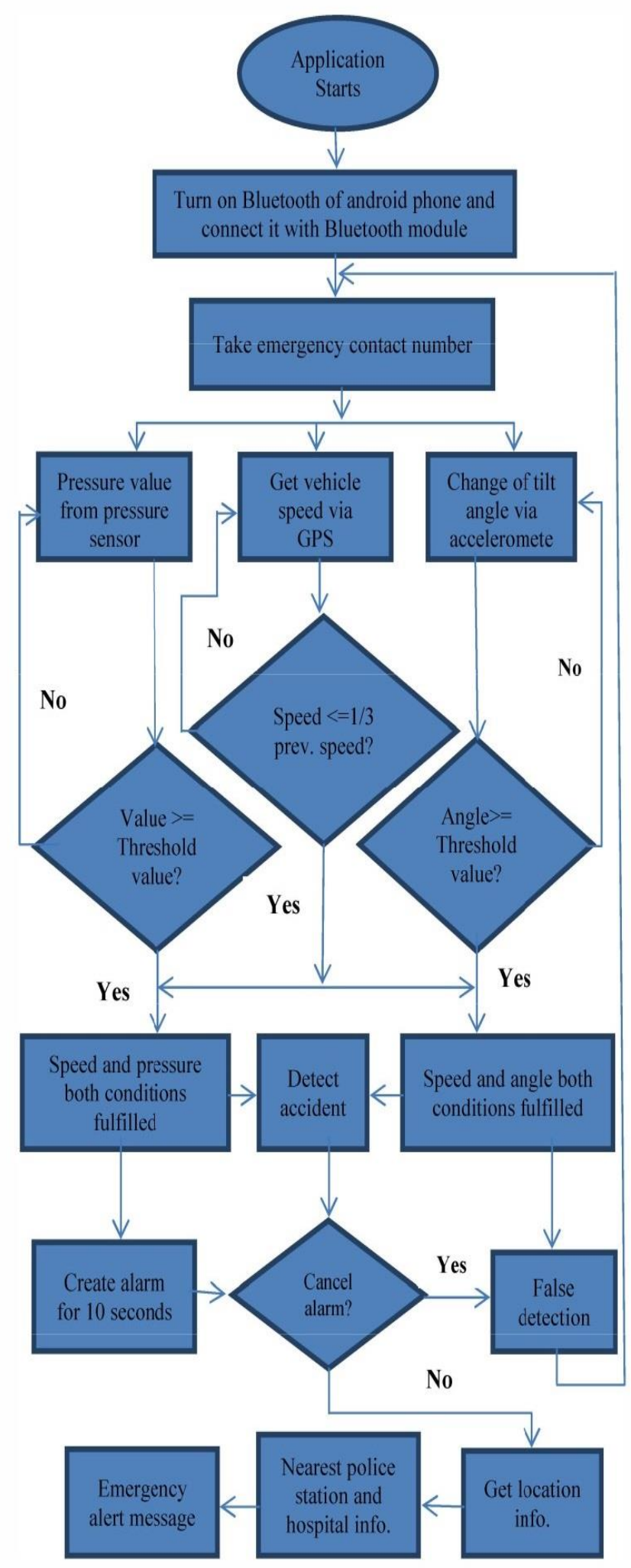

\section{METHODOLOGY}

In this proposed system Microcontroller being powered by DC supply that switches on the GSM. After a while, the input-output port gets ready, and accident detection process is being started. GPS sends reading data to micro-controller continuously as well as Vibration sensor takes vibration data. The vibration sensors present state is always high. After exceeding its limit, it turns into a low signal. This weak signal satisfied a condition of the microcontroller. After satisfied condition, current latitude and longitude by GPS and a code generated message will ready for send. In this time, a warning message will be shown in LCD, and a LED also blazes. The condition for a while for pressing the acknowledge button to reset. After over the period, GSM sends SMS to the nearest hospital and police. Block Diagram of the proposed system is shown in Figure 1.

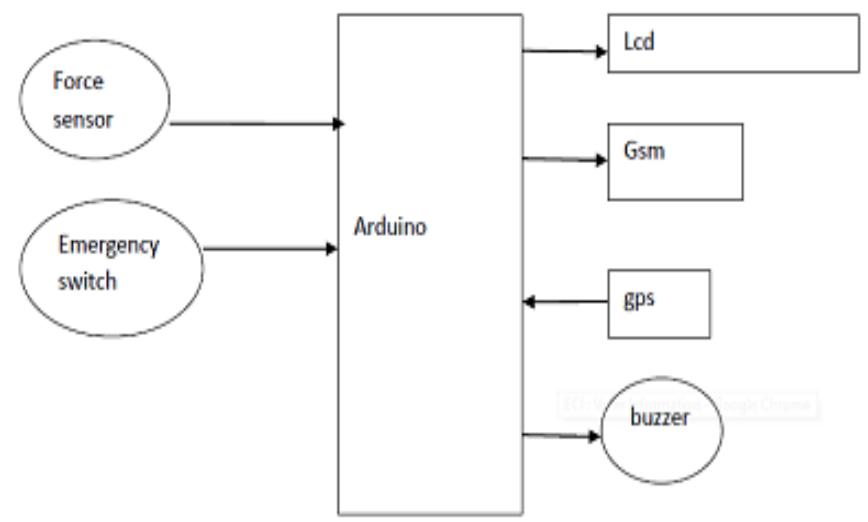

Fig: 1

Fig. 1. System architecture 


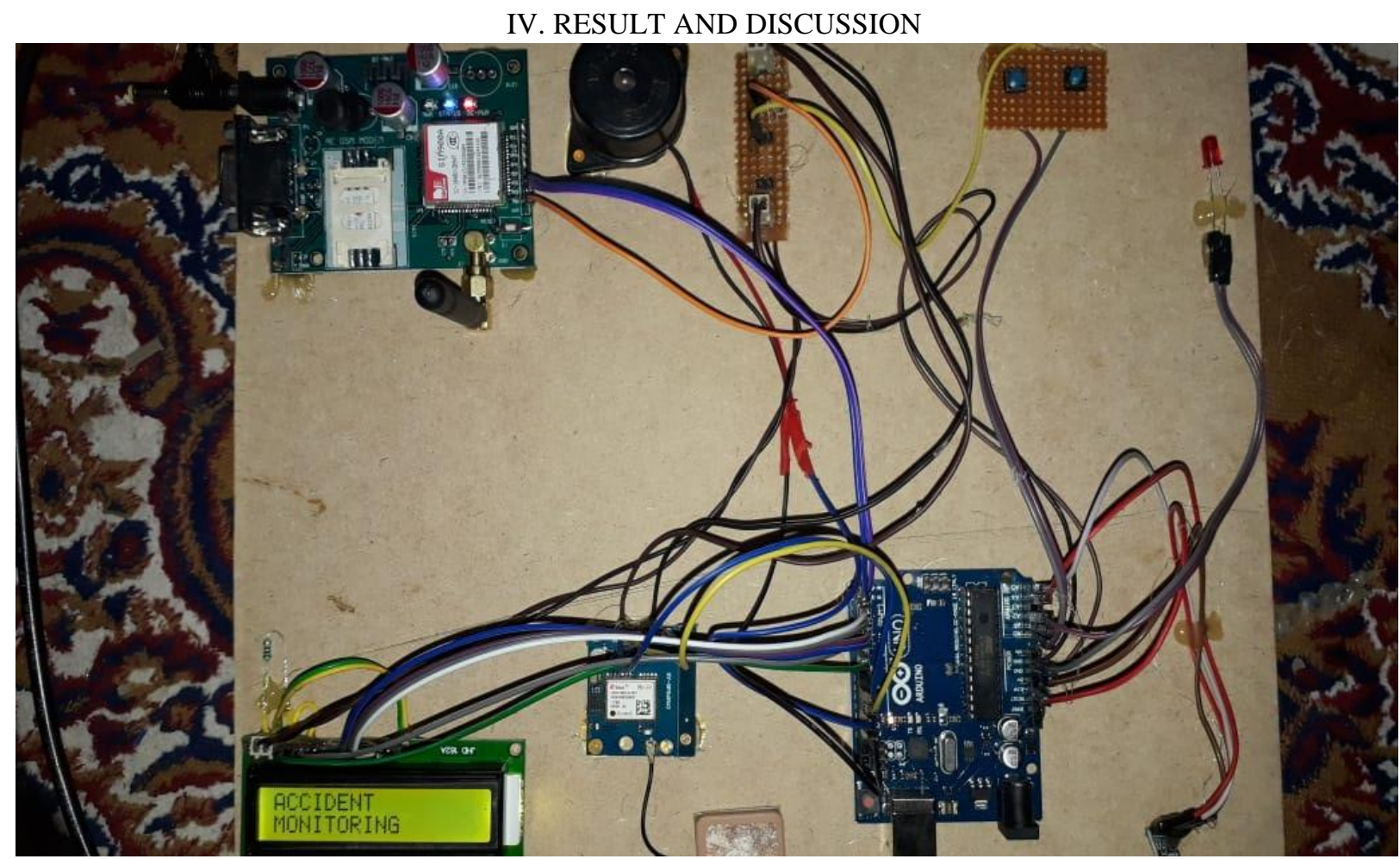

Fig 2: complete experimental setup of the project with sensor, gsm, gps, lcd and arduino controller

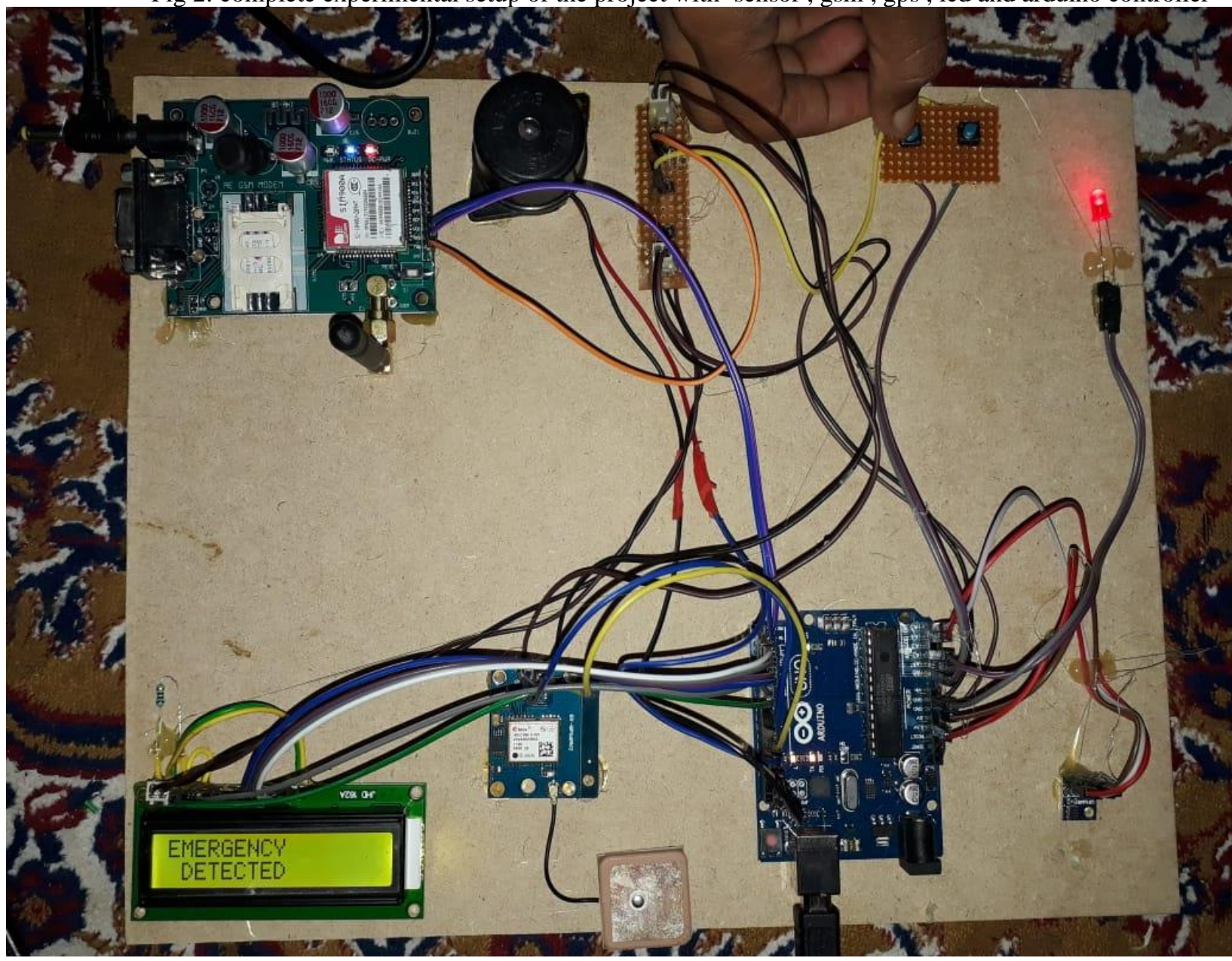

Fig 3: emergency button used lcd displays information and message will be sent to the vehicle owner 


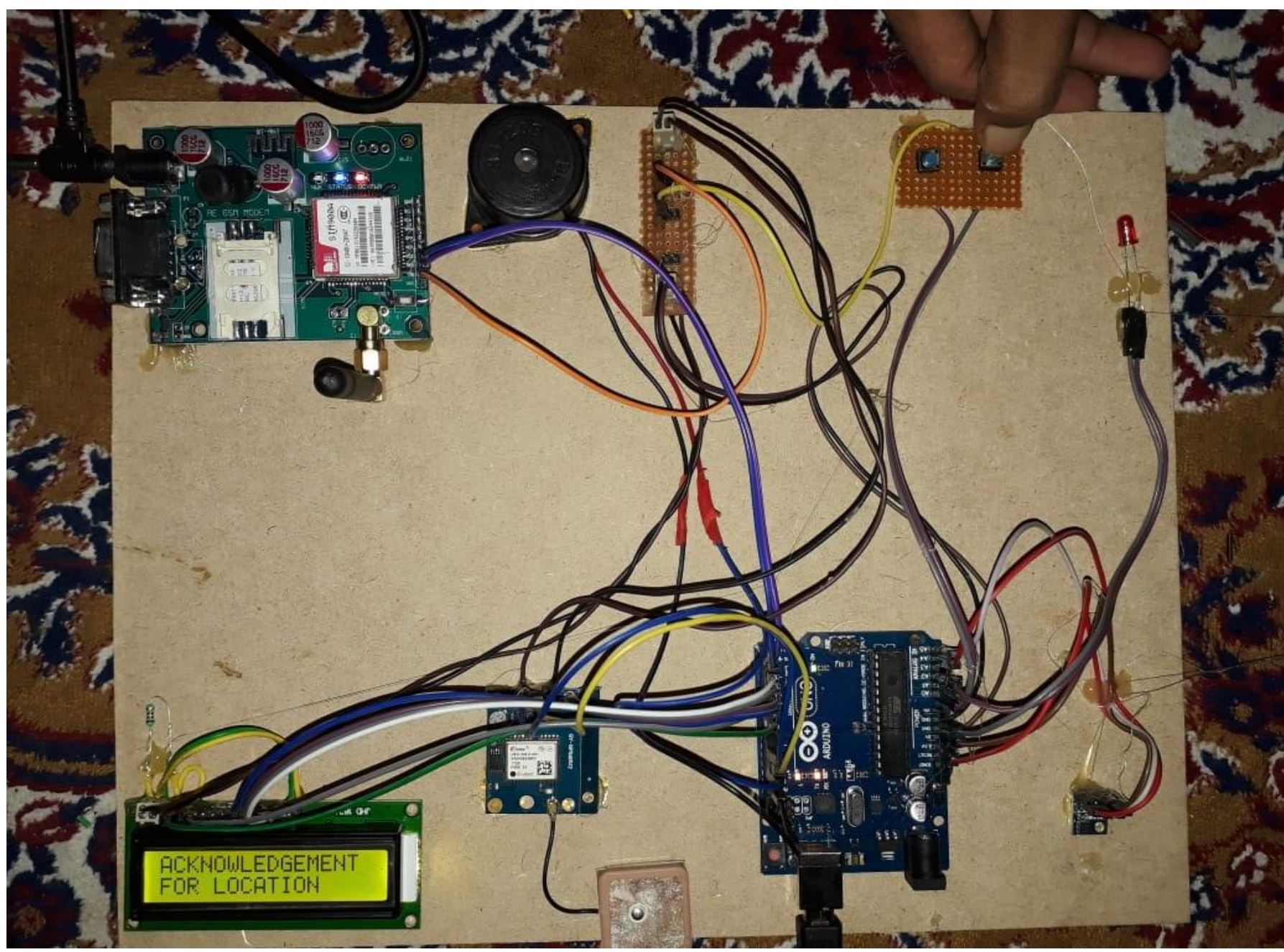

Fig 4:in the above image information is displayed when acknowledgement switch used by driver and a gps location will be sent to the vehicle owner with a gsm message

\section{CONCLUSION}

In this paper, we have shown that road accident can be detected efficiently by using some particular parameters. Our proposed approach capable of deciding whether a situation is an accident or not and if so, then immediately traces nearest police station as well as hospital and send emergency alert message for help. Besides, we have demonstrated the reduction of false alarm in a greater extent compared to other previous works. Though the system requires a continuous Internet connection, but this it is very much cost effective and can be applied significantly in the practical world. In the future, we have a plan to consider more parameters for detecting accident and developing the application in a single device. Hence, the application would play a crucial role in post-accident services and could mitigate the effect due to accident remarkably.

\section{REFERENCES}

[1] Highlights of 2009 Motor Vehicle crashes, Tramc Safety Facts, Research Notes, NHTSA (National Highway traffic Safety Administration) [Online], Accessed on 16 October 2011.

[2] N. Virtanen, A Schirokoff and 1. Luom, "Impacts of an automatic emergency call system on accident consequences," 18th ICTCT, Workshop Transport telemetric and safety, 2005.
[3] S. M. Tang and H. 1. Gao, "Tramc-incident detection-algorithm based on nonparametric regression," IEEE Transactions on Intelligent Transportation Systems, 2005.

[4] G. Rose, "Mobile Phones as Traffic Probes: Practices, Prospects and Issues," Transport Reviews, 2006.

[5] P.Mohan,Y.N.Padmanabhan, and R.Ramjee, "Nericel1:richmonitoring of road and traffic conditions using mobile smartphones," in Proceedings of the 6th ACM conference on Embedded network sensor systems, 2008.

[6] D. A Whitney and 1. 1. Pisano T ASC, Inc., Reading, Massachusetts, "Auto Alert: Automated Acoustic Detection of Incidents," IDEA project, 15 October 2011.

[7] C. Thompson, 1. White, B. Dougherty, A Albright and D.C Schmidt, "Using Smartphones to Detect Car Accidents and Provide Situational Awareness to Emergency Responders," in Proceedings of 3'd Mobile Wireless Middleware, Operating Systems, and Applications Conference, 2010.

[8] J. Yoon, B. Noble and M. Liu, "Surface street traffic estimation," in Proceedings of 5th International Conference on Mobile Systems, Applications,and Services, 2007.

[9] Md. Syedul Amin, Jubayer Jalil, M. B. I. Reaz, "Accident Detection and Reporting System using GPS, GPRS and GSM Technology," in Proceedings of International Conference on Informatics, Electronics \& Vision, 2012.

[10] Chalermpol Saiprasert and Wasan Pattara-Atikom, "Smartphone Enabled Dangerous Driving Report System," in Proceedings of 46th Hawaii International Conference on System Sciences, 2013.

[11] In Jung Lee, "An Accident Detection System on Highway Using Vehicle Tracking Trace," ICT Convergence, 2011. 


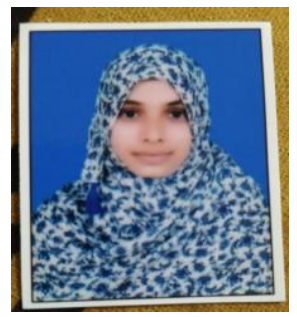

Ms.Sana bearing USN 3VY18LVS13,branch vlsi and embedded system, from vtu regional center kalaburagi is doing Masters and her area of research include working on sensors and 8 bit controllers

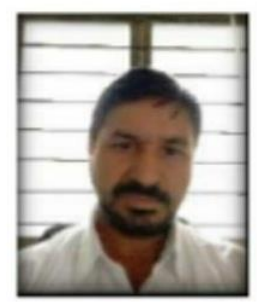

Dr Ravindra P Rajput is a professor inVTU, CPGS, Kalaburagi .He has finished his PhD from Mysore University .He has published 10 journals papers. He has 22 years of experience in teaching. His areas of interest are VLSI and Embedded System, Microcontroller and Microprocessor .He is presently working on the design of very high speed multiplexer circuit for both signed and unsigned numbers. 